\title{
Effect of endothelium-derived relaxing factor on renin secretion from isolated mouse renal juxtaglomerular cells
}

\author{
K. SCHRICKER ${ }^{1}$, 'T. RITTHALER' ${ }^{1}$, B. K. KR ÄMER ${ }^{2}$ and A. KURTZ1 \\ ${ }^{1}$ Physiologisches Institut der Universität Regensburg and ${ }^{2}$ Klinik and Poliklinik für Innere \\ Medizin II der Universität Regensburg
}

\begin{abstract}
SChricker, K., Ritthal.f, T., Krämer, B. K. \& KURTZ, A. 1993. Fffect of endothelium-derived relaxing factor on renin secretion from isolated mouse renal juxtaglomerular cells. Acta Physiol Scand 149, 347-354. Received 29 March 1993, accepted 1 June 1993. ISSN 0001-6772. Physiologisches Institut der Universität Regensburg, and Klinik und Poliklinik für Innere Medizin II der Universität Regensburg, Germany.
\end{abstract}

This study aimed to examine the direct influence of native endothelium derived relaxing factor (EDRF) on renin secretion. To this end isolated mouse renal juxtaglomerular cells were cocultured with bovine aortic endothelial cells which produced and released significant amounts of EDRF as assayed by guanylate cyclase activities which were measured separately in endothelial and juxtaglomerular cells as well as in the cocultures of juxtaglomerular with endothelial cells. EDRF production was blunted in the absence of extracellular L-arginine and in the presence of $N^{t \prime \prime}$-nitro-L-arginine (L-NAG; $200 \mu \mathrm{M})$.

Inhibition of endothelial EDRF production by removal of arginine or addition of $L$ NAG was associated with a significant decrease of renin secretion from the cocultures while the same regimen had no effect on renin secretion from JG cells alone. Exogeneous generation of nitric oxide by the addition of sodium nitroprusside $(100 \mu \mathrm{M})$ stimulated renin secretion in the cocultures both at normal and inhibited EDRF formation as well as from juxtaglomerular cells alone.

These findings suggest that native EDRF released from vascular endothelial cells is a stimulatory signal for renin secretion from renal juxtaglomerular cells.

Key' mords: juxtaglomerular cells, renin release, EDRF.

Endothelium derived relaxing factor (EDRF), which is considered to be nitric oxide could be of relevance for the regulation of renin secretion for two major reasons. First, renal juxtaglomerular (JG) cells which produce and release the protease renin are modified vascular smooth cells and are therefore in direct contact with vascular endothelial cells (Barajas 1979). As there is abundant evidence that EDRF of endothelial origin essentially modulates the function of vascular smooth muscle cells (Furchgott \& Vanhoutte 1989) it is conceivable that the same

Correspondence: Dr Karin Schricker, Physiologisches Institut, Universität Regensburg, Postfach 101042, W-8400 Regensburg, Germany. holds true for JG cells. Secondly, high level expression of constitutive NO-synthase has recently been demonstrated in renal tubular macula densa cells which are also direct neighbours of JG cells (Mundel et al. 1992, Wilcox et al. 1992).

The influence of EDRF on renin secretion has previously been examined in several studies but based on indirect evidence opposite interpretations were derived about the role of EDRF in the control of renin secretion. A stimulatory effect of EDRF on renin secretion was inferred from experiments with isolated perfused rat kidneys in which inhibitors of NO-synthase were found to attenuate basal and pressure dependent renin secretion (Gardes et al. 1992, 
Scholz \& Kurtz, 1993). An inhibitory effect of EDRF on renin secretion on the other hand was inferred from in vitro experiments with kidney slices (Vidal et al. 1988, Beierwaltes et al. 1992) and from an in vivo study with rats (Sigmon $e t$ al. 1992). All of these findings and interpretations were obtained with rather complex models and the seemingly contradictory findings about the effect of EDRF may be the result of combined direct and indirect effects of EDRF which in their sum may depend on the experimental model used.

In order to obtain more clear information about the role of EDRF in the control of renin secretion it was necessary to study the direct effect of EDRF on renin secretion from isolated renal juxtaglomerular cells. A recent coculture study with renal JG cells and bovine microvascular endothelial cells has provided evidence that endothelial cells in fact modulate renin secretion from JG cells (Kurtz et al. 1991). Since the role of EDRF in this context had not been examined systematically in that study, it appeared reasonable to study the effect of native EDRF by utilizing cocultures of JG cells with endothelial cells that release substantial amounts of EDRF in a regulatible fashion.

The results obtained suggest that native EDRF is a stimulatory rather than an inhibitory signal for renin secretion.

\section{METHODS}

Culture of endothelial cells. Primary cultures of bovine aortic endothelial cells were established as described previously (Lückhoff et al. 1987). In brief, bovine thoracic aortas were obtained from a slaughterhouse. Blood was cleaned from aorta by rinsing twice with phosphate buffered saline and then enzymatic digestion was performed by incubating the aorta with $50 \mathrm{ml}$ of collagenase $\left(1 \mathrm{mg} \mathrm{ml} \mathrm{m}^{-1}\right)$ for $1 \mathrm{~h}$. After incubation the endothelial cells were rubbed off the intimal surfaces and plated in $\alpha$-MEM containing $10 \%$ FCS. After $5 \mathrm{~d}$ of culture endothelial cells reached confluence and were subcultured twice a week at a ratio of $1: 5$. Cloned capillary endothelial cells from bovine adrenal glands (Furie et al. 1984) were handled as described previously (Kurtz et al. 1991). Growing slower than primary cultured endothelial cells, they were subcultured only once a week at a ratio of $1: 4$. The endothelial cells were grown in 24-well plates for deter- mination of cyclic GMP accumulation and in 96-well plates for coculture experiments on renin secretion.

Culture of mouse juxtaglomerular cells. Mouse juxtaglomerular cells were isolated as described previously (Della Bruna et al. 1991). For one cell preparation, four male C57B16 mice $(+6 \mathrm{wk}$ old) who had free access to normal food and water were killed by cervical dislocation. The kidneys were extirpated, decapsulated and minced with a razor blade. The minced tissue was incubated under gentle stirring for $70 \mathrm{~min}$ at $37^{\circ} \mathrm{C}$ in a solution of $30 \mathrm{ml}$ buffer $1(130 \mathrm{~mm}$ $\mathrm{NaCl}, 5 \mathrm{~mm} \mathrm{KCl}, 2 \mathrm{~mm} \mathrm{CaCl}_{2}, 10 \mathrm{~mm}$ glucose, $20 \mathrm{~mm}$ sucrose, $10 \mathrm{~mm}$ tris-HCl, pH 7.4) supplemented with $0.25 \%$ trypsin (Sigma, St Louis, MO, USA) and $0.1 \%$ collagenase (Boehringer Mannheim, Germany).

After enzymatic dissociation, the tissue was sieved over a $22-\mu \mathrm{m}$ screen. Single cells passing the screen were collected, washed and resuspended in $8 \mathrm{ml}$ of buffer 1 and then further separated using Percoll (Pharmacia, Uppsala, Sweden) density gradients. The obtained cell suspension was added to two tubes each containing $30 \mathrm{ml} \mathrm{30 \%}$ isoosmotic Percoll in buffer 1. After $25 \mathrm{~min}$ centrifugation at $4{ }^{\circ} \mathrm{C}$ and $27000 \mathrm{~g}$ four cell layers with different specific renin activity were obtained.

The cellular layer $\left(\mathrm{d}=107 \mathrm{~g} \mathrm{ml}^{-1}\right)$ which had the highest specific renin activity was used for cell culture. These cells were washed in buffer 1 and resuspended in $6 \mathrm{ml}$ of RPMI 1640 medium (Amimed, Basel, Switzerland) containing $0.66 \mathrm{U} \mathrm{ml}^{-1}$ insulin, $100 \mathrm{U} \mathrm{ml}^{-1}$ penicillin, $100 \mu \mathrm{g} \mathrm{ml}^{-1}$ streptomycin and $2 \%$ fetal calf serum (FCS).

The cultures were distributed in $600 \mu \mathrm{l}$ portions into $24-w e l l$ plates or in $100 \mu \mathrm{l}$ portions into 96 -well plates and incubated at $37^{\circ} \mathrm{C}$ in a humified atmosphere containing $5 \% \mathrm{CO}_{2}$ in air.

Cocultures of juxtaglomerular with endothelial cells. For the cocultures the endothelial cells were seeded in 24-well or 96-well plates and grown for $3 \mathrm{~d}$. On the fourth day the culture medium was removed and renal cortical cell suspensions prepared as described above were seeded at the same number as in the absence of endothelial cells in $600 \mu \mathrm{l}$ (for 24-well plates) or $100 \mu 1$ (for 96-well plates) of their culture medium. Twenty-four hours later the culture medium together with the nonattached cells was removed, the cultures were washed twice and 
then $250 \mu l$ (24-well plates) or $50 \mu 1$ (96-well plates) of fresh medium were added and the experiments were started.

Experiments on renin secretion. Experiments on renin secretion from JG cells alone or from cocultures with endothelial cells were started after 24 h of primary culture of the renal cells in 96-well plates. At this time point the culture medium was removed and the cultures were washed twice with RPMI 1640 medium containing $2 \%$ FCS. Then fresh and prewarmed culture medium supplemented with $0.66 \mathrm{U} \mathrm{ml}^{-1}$ insulin, $100 \mathrm{U} \mathrm{ml}^{-1}$ penicillin, $100 \mu \mathrm{g} \mathrm{ml}^{-1}$ streptomycin and 2\% FCS together with the chemicals to be tested was added. Experiments on renin secretion were performed for 3 or $20 \mathrm{~h}$. At the end of the experiment supernatants were collected and centrifuged at $500-1000 \mathrm{~g}$ and room temperature in a Heraeus centrifuge in order to remove cellular debris. The supernatants were then stored at $-20{ }^{\circ} \mathrm{C}$ for further processing.

Cells were lysed by adding to each culture well $50 \mu 1$ of phosphate buffered saline (PBS) containing $0.1 \%$ of Triton $\mathrm{X}-100$ and shaking for $45 \mathrm{~min}$ at room temperature. The lysed cells were stored at $-20^{\circ} \mathrm{C}$ for further processing.

Renin secretion rates were estimated from the appearance rate of renin activity in the culture medium. To minimize differences among different cell cultures preparations, renin secretion rates were calculated as fractional release of total renin [i.e. renin release $/($ renin released + renin remaining in the cells)].

Renin activity was determined by its ability to generate angiotensin I from the plasma of bilaterally nephrectomized rats. Angiotensin I was measured by radioimmunoassay (RIA) (Sorin, Düsseldorf, Germany). Each experiment represents the mean of five replicate wells.

Measurement of cyclic GMP formation. Cyclic GMP accumulation was measured as an indicator for guanylate cyclase activity. For measurement of cyclic GMP accumulation endothelial and JG cells as well as cocultures of both were grown in 24-well plates. Ten minutes before harvesting of the cells the phosphodiesterase activity was inhibited by 3-isobutyl-1-methylxanthine $(0.5 \mathrm{~mm})$. Accumulated cyclic GMP was extracted from the cells by adding icecold $95 \%$ ethanol containing $20 \mathrm{mM} \mathrm{HCl}$ to the culture wells and setting the plate to $-20^{\circ} \mathrm{C}$ for at least $20 \mathrm{~h}$. After evaporation of the ethanolic solution, samples were resuspended in assay buffer and the content of cGMP was determined after succinylation by RIA (Amersham, Braunschweig, Germany). Each experiment represents the mean of duplicate culture wells.

Assay of protein. Protein concentration in cellular lysates was determined using the Bio Rad Protein Assay Kit.

Chemicals. Culture media were purchased from Biochrom, Berlin, Germany. L-NAG, sodium nitroprusside, bradykinin and 3isobutyl-1-methylxanthine were obtained from Sigma International.

Statistics. Levels of significance were calculated utilizing Student's unpaired $t$-test. $P<$ 0.05 was considered significant.

\section{RESULTS}

First experiments were performed in order to screen endothelial cell cultures for their capability to produce EDRF. As an indicator for the presence of EDRF guanylate cyclase (GC) activity was measured which is known to be stimulated by EDRF (Mülsch et al. 1987). A comparison of primary cultures of bovine aortic

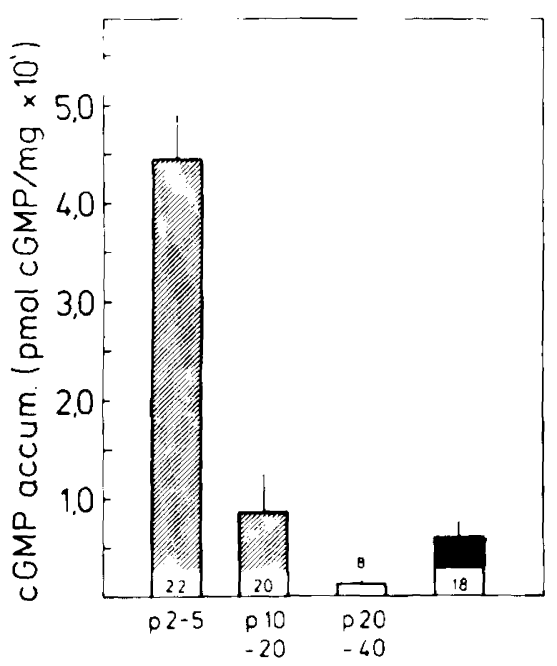

Fig. 1. Accumulation of cyclic GMP as a measure of guanylate cyclase activity in cultures of bovine aortic endothelial cells (BAEC; $\square$ ) at lower $(2-5)$ and higher (10-20) passages, in a transfected cell line of bovine microvascular endothelial cells (BMEC; $\square$, passage 20-40) and in primary cultures of mouse renal cells enriched in juxtaglomerular (JG $\square$ ) cells. Data are means \pm SEM. The numbers of experiments are indicated at the bottoms of the columns. 


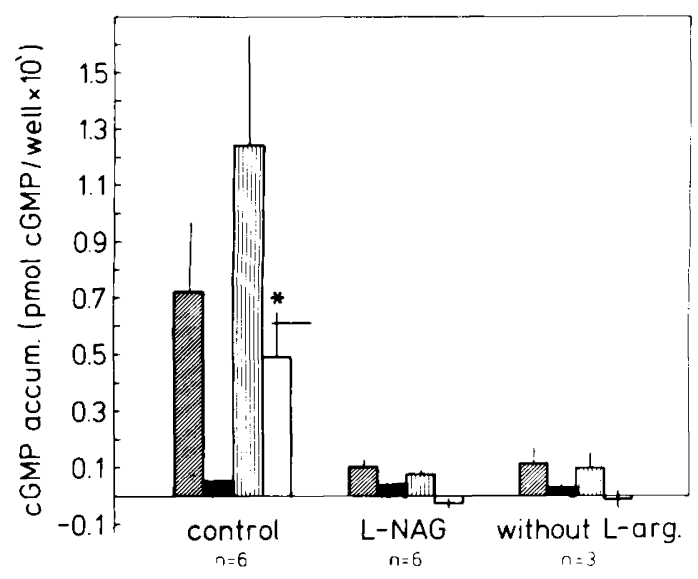

Fig. 2. Cyclic GMP accumulation in BAEC cultures ( ; passage 2-5), JG cell cultures $(\square)$ and cocultures of BAEC and JG cells ( in the presence of $200 / \mu N^{(t \prime \prime}$-nitro-L-arginine (LNAG) and in the absence of $L$-arginine. $\square$ represents the difference of cGMP accumulation between the cocultures and the sums of BAEC and JG cell cultures of each individual experiment. Data are means \pm SEM. The numbers of individual experiments are given at the bottom of the figure. Asterisk $P<0.05$.

endothelial cells with a transfected stable cell line of bovine adrenal capillary endothelial cells showed that the aortic endothelial cells displayed a higher basal GC activity than did the adrenal endothelial cells (Fig. 1). GC activity in the primary cultures of the aortic cells were dependent on the passage number, in a way that lower passages had a higher basal GC activity than higher passages (Fig. 1). For further evidence that the GC activity was indicative for EDRF release the GC stimulating activity in the endothelial cells was examined to ascertain whether it was diffusible to cocultured juxtaglomerular cells. To this end bovine aortic endothelial cells at low passage $(2-5)$ were grown in single cultures or in coculture with mouse renal cells enriched in juxtaglomerular cells. GC activity was then determined for the single cultures of JG cells and endothelial cells and from the cocultures established from the respective cell batches. As shown in Figure 2, GC activity in cocultures of endothelial with juxtaglomerular cells was markedly higher than the sum of the respective $\mathrm{GC}$ activities found in endothelial cells alone and in juxtaglomerular cells alone, while the cell mass in the cocultures corresponded well with the sum of respective cell masses of endothelial and JG cells $(198 \pm 37$,

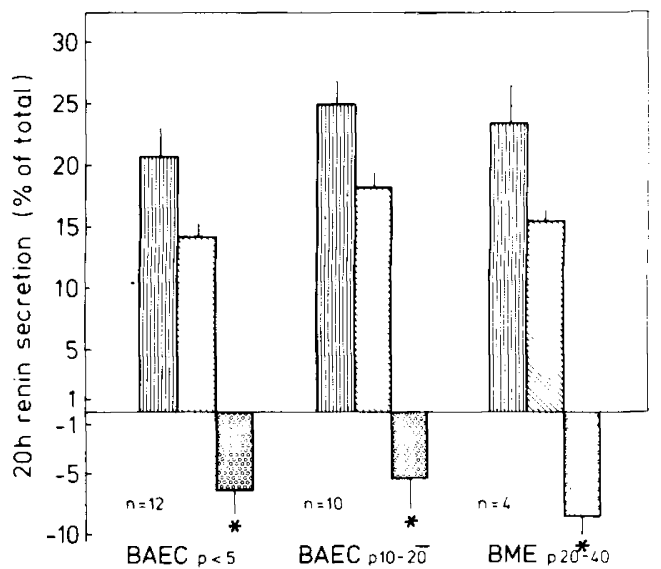

Fig. 3. Twenty-hour renin secretion rates from cultured mouse JG cells (四) in the absence and in the presence of bovine aortic endothelial cells (BAEC) at low (2-5) and at higher passage $(10-20)$ and in the presence of bovine microvascular endothelial (BME) cells (passage $20-40$ ). 图 represents the difference of renin secretion rates between JG cells alone and cocultures $(\mathbb{\mathbb { N }})$ for the individual experiments. Renin secretion rates are expressed as a percentage of the total renin activity present in the cultures as described in the materials and methods section. Total renin activity was $209 \pm 14.2 \mathrm{ng} \mathrm{AngI} \mathrm{h}{ }^{-1}$ per culture well in the absence and $273 \pm 9.4 \mathrm{ng}$ AngI $\mathrm{h}^{-1}$ per culture well in the presence of endothelial cells. Data are means $\pm S E M$. The number of individual experiments are given at the bottom of the figure. Asterisks indicate $P<0.05$.

$91 \pm 39$ and $272 \pm 41 \mu \mathrm{g}$ well ${ }^{-1}$ for endothelial cells, JG cells and cocultures respectively). For comparison the effect of sodium nitroprusside (SNP), a well known donor of NO (Murad et al. 1987), was examined on GC activity in JG cells. With $100 \mu \mathrm{M}$ SNP cGMP accumulation in JG cells cultures alone increased from $54 \pm 19$ to $238 \pm 51 \mathrm{fmol}^{\text {well }}{ }^{-1}$, the specific difference of the individual cultures being $184 \pm 35 \mathrm{fmol}$ well $^{-1}$ (means $\pm S E M ; n=5$ ) after $3 \mathrm{~h}$ of incubation. This increment of cGMP accumulation was even less than that achieved with the coculture with BAEC which amounted to $490 \pm 160$ fmol cGMP well $^{-1}$ (Fig. 2). The GC activity in endothelial cells and in the cocultures of endothelial cells with JG cells was markedly diminished in the absence of $\mathrm{L}$-arginine and in the presence of the arginine antagonist L-NAG (Fig. 2). Notably, there was no enhancement of cGMP accumulation in the JG cells by coculture with endothelial cells in the absence of $\mathrm{L}-$ 


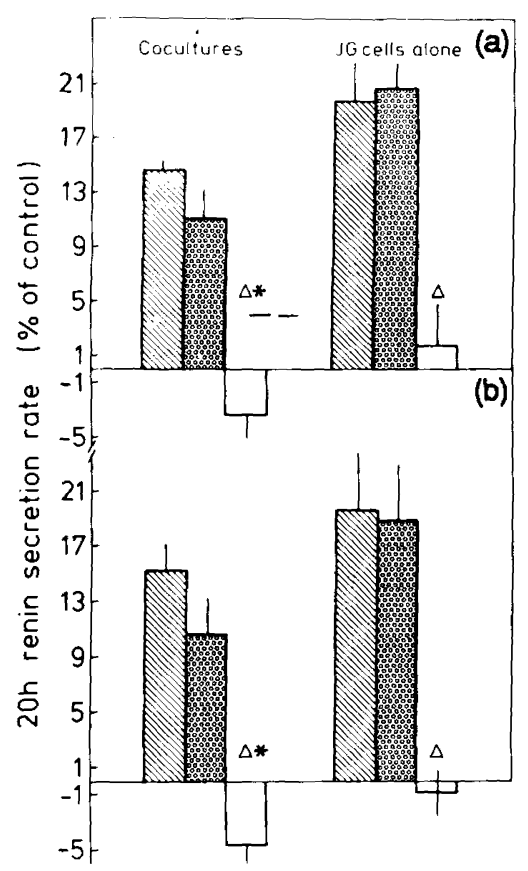

Fig. 4. (a) Twenty-hour renin secretion rates from JG cells alone and from cocultures with BAEC at low passage under control conditions $(\mathbb{\nabla}$ and in the presence of $200 \mu \mathrm{M} \mathrm{N} N^{\omega}$-nitro-L-arginine (雒)). $\triangle$ represents the difference of renin secretion rates between the presence and the absence of L-NAG in the individual experiments. Data are means \pm SEM of six experiments each. (b) Twenty-hour renin secretion rates from JG cells alone and from cocultures with $B A E C$ at low passage under control conditions $(\mathbb{Q}$ and in the absence of L-arginine (圈)). $\triangle$ represents the difference of renin secretion rates between the absence and the presence of L-arginine. Data are means \pm SEM of seven experiments each. Asterisks indicate $P<0.05$.

arginine and in the presence of L-NAG (Fig. 2). Another aim was to find conditions for reproducible stimulations of EDRF release from the endothelial cells. As the constitutive NOsynthase is activated by an influx of calcium into the cell (Lückhoff et al. 1990) the authors concentrated, in this context, on hormones increasing calcium in the endothelial cells such as bradykinin (Morgan-Boyd et al. 1987). Bradykinin (100 nM) led to a transient $50 \%$ increase of cGMP accumulation in the endothelial cells at higher passages which lasted for $10 \mathrm{~min}$ maximally after addition of the hormone (not shown).

Experiments were also performed to characterize the influence of endothelial cells on renin

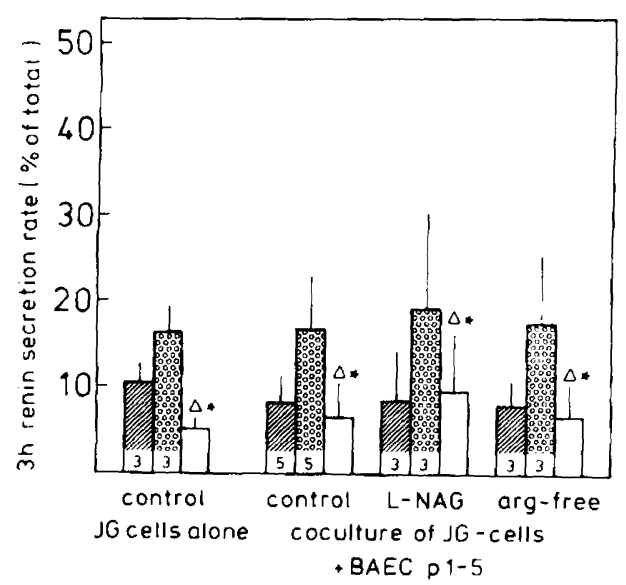

Fig. 5. Effect of sodium nitroprusside $(100 \mu \mathrm{M})$ on renin secretion from JG cells alone and from cocultures with BAEC at low passage during $3 \mathrm{~h}$ of incubation. The cocultures were examined under control conditions, in the presence of $200 \mu \mathrm{M} \mathrm{L}-\mathrm{NAG}$ and in the absence of $\mathrm{L}$-arginine. $\triangle$ represents the effect of SNP in the cultures $(\mathbb{Q}$, without SNP; 閶, with SNP [100 mM]). Data are means \pm SEM. The numbers of experiments are given at the bottoms of the columns. Asterisks indicate $P<0.05$.

secretion from cultured JG cells. Total renin activity in JG cells, lysed after $20 \mathrm{~h}$ of primary culture, was $15.1 \pm 0.76 \mu \mathrm{g} \mathrm{ANGI} \mathrm{h}{ }^{-1} \mathrm{mg}$ protein $^{-1}$ (mean \pm SEM, $n=8$ ); this corresponded to $225 \pm 11.4 \mathrm{ng}$ ANGI $h^{-1}$ culture well ${ }^{-1}$. In the presence of endothelial cells total renin activity increased slightly to $276 \pm 9.8 \mathrm{ng} \mathrm{ANGI} \mathrm{h}^{-1}$ culture well ${ }^{-1}$, because endothelial cells favoured the attachment of JG cells. Nevertheless it was possible to make a quantitative analysis of renin secretion by comparing fractional renin release of the cell cultures (i.e. renin released/renin released + renin remaining in the cells). This fractional renin release has been found to be independent of JG cell number and of total renin activity (Kurtz et al. 1991). As shown in Figure 3 basal renin secretion rates were lower in the presence than in the absence of endothelial cells. This attenuation of basal renin release by endothelial cells was not related to their capability of EDRF production, since aortic endothelial cells at low and higher passages as well as microvascular endothelial cells were similarly effective in decreasing basal renin secretion (Fig. $3)$. Inhibition of EDRF formation by the addition of L-NAG or by the omission of L-arginine 
further decreased renin secretion in the cocultures but not in the JG cells alone (Fig. 4).

To further increase the concentration of $\mathrm{EDRF} / \mathrm{NO}$ in the cocultures with higher basal EDRF output we examined the effect of sodium nitroprusside on the secretion of renin. Sodium nitroprusside $(100 \mu \mathrm{M})$ stimulated renin secretion in the JG cells alone and in the cocultures to similar extents (Fig. 5). A similar stimulatory effect of SNP in the cocultures was also found in the absence of $\mathrm{L}$-arginine and in the presence of $N^{(t)}$-nitro-L-arginine (Fig. 5).

\section{DISCUSSION}

This study aimed to examine the direct effect of native EDRF on renin secretion from renal juxtaglomerular cells. As a source of EDRF low passages of primary cultures of bovine aortic endothelial cells were considered for several reasons. Firstly, the cells had a high basal endogenous GC activity which is known to be determined by EDRF (Boulanger et al. 1990). Secondly, the GC stimulating activity was diffusible from endothelial cells to cocultured JG cells. Finally, the GC stimulating activity was dependent on the availability of L-arginine in a fashion characteristic for EDRF (Palmer et al. 1988, Moore et al. 1990).

A comparison of the effects of endogenous EDRF on GC activity in JG cells with that obtained with the NO-donor nitroprusside showed that the release of EDRF from the endothelial cells was quite substantial. Therefore, it appears that cocultures of bovine aortic endothelial cells with renal juxtaglomerular cells represent an experimental model in which renal JG cells are continuously exposed to relevant amounts of native EDRF. Basal renin secretion rates from JG cells were significantly lower in the presence of endothelial cells compared with the absence of endothelial cells, a finding that confirms a previous idea obtained with cocultured transfected adrenal endothelial cells (Kurtz et al. 1991). Since this attenuation of renin secretion by endothelial cells was not related to their capability to produce EDRF (Fig. 1), it is unlikely that this inhibitory effect was due to the release of EDRF. Possible candidates for the inhibition of renin secretion by endothelial cells could be endothelin (Moe 1991), lipoxygenase products (Antonipillai 1987) or other endothelial autacoids. The role of EDRF in this endothelial action was examined by inhibition of EDRF production by removal of arginine or by addition of L-NAG; two manoeuvres which both decreased renin secretion from the JG cells in coculture, while removal of arginine or addition of $L-N A G$ had no effect on renin release from JG cells alone (Fig. 4). Exogenous generation of nitric oxide by the addition of nitroprusside stimulated renin secretion from JG cells alone and from JG cells in coculture independently on the availability of L-arginine (Fig. 5). From the sum of these findings it is inferred that native EDRF has a direct stimulatory effect on renin secretion from renal JG cells. Unfortunately, the authors were unable to determine the direct effect of an enhanced EDRF release on renin secretion, because we did not find suitable conditions under which endogenous EDRF release could be increased over the time span of hours as it was required for the study of renin secretion from cultured JG cells. The use of calcium ionophores which would increase the cytosolic calcium concentration for a longer time in this context is problematic for two major reasons. First they are cytotoxic during prolonged incubation, and secondly they would also increase the calcium concentration in the $\mathrm{JG}$ cells, in which calcium is considered to block renin secretion (Hackenthal et al. 1990).

Nonetheless the stimulatory effect of nitroprusside on renin secretion, however, could be taken as an indirect evidence that a further and continuous increase of basal NO release could, in principle, stimulate renin secretion.

These findings suggesting a stimulatory effect of EDRF on renal JG cells are in accordance with previous findings obtained with isolated perfused kidneys (Gardes et al. 1992, Scholz \& Kurtz 1993) but they are at variance with findings obtained with kidney slices. There it was found that a superfusate from aortic rings inhibited renin secretion from kidney slices if acetylcholine was added to the superfusate (Vidal et al. 1988). In another study it was demonstrated that addition of nitro-L-arginine methylester ( $\mathrm{L}-$ NAME) to incubated kidney slices increased basal renin release (Beierwaltes et al. 1992). An inhibitory effect of EDRF on renin secretion was also inferred from an in vivo study in which treatment of anaesthetized rats with propranolol and L-NAME led to a $50 \%$ increase of plasma renin activity (Sigmon et al. 1992) A clear 
explanation for these obvious divergent results cannot yet be offered. 'The authors wish to mention, however, that it is rather difficult to distinguish between direct and indirect effects of EDRF in complex preparations such as kidney slices or whole animals. It was suggested recently that EDRF produced by the macula densa cells may interfere with the macula densa signal influencing afferent arteriolar tone and renin secretion from the juxtaglomerular apparatus (Wilcox et al. 1992). Therefore, it is conceivable that general stimulation or inhibition of EDRF formation in total renal tissue may influence renin secretion not only by a direct effect on JG cells but also by modulating the as yet unidentified macula densa signal.

Finally, the signal pathway along which EDRF directly stimulates renin secretion from JG cells deserves consideration. Although stimulation of GC activity is the best characterized signalling system for EDRF (Ignarro 1989) there is, however, increasing evidence for cellular effects of $\mathrm{EDRF}$ that are not related to $\mathrm{CGMP}$ formation (Brüne et al. 1989, Garg et al. 1991; HeuzéJoubert et al. 1992). The authors have obtained evidence recently that the stimulatory effect of the NO-donor nitroprusside on renin secretion from isolated JG cells is not mediated by cGMP (Schricker \& Kurtz, in press). Assuming that these findings are transferable to the effects of native EDRF it appears likely that the direct stimulatory effect of EDRF on JG cells is mediated by an as yet unknown pathway. Clarification of this pathway will be an aim of future work.

We thank K. H. Götz and M. Hamann for doing the artwork. This study was financially supported by a grant from the Deutsche Forschungsgemeinschaft (Ku 859/2-1) and by a grant from the Doktor Robert Pfleger-Stiftung.

\section{REFERENCES}

A.vtonipillai, I., Nadler, J.L., Robin, E.C. \& HorTon, R. 1987. The inhibitory role of $12-$ and 15-lipoxygenase products on renin release. $\mathrm{Hy}$ pertension 10, 61-66.

Barajas, L. 1979. Anatomy of the juxtaglomerular apparatus. Am f Physiol 236, F333-F343.

Beierwaltes, W.H. \& Carretero, O.A. 1992. Nonprostanoid endothelium-derived factors inhibit renin release. Hypertension 19, II-68-II-73.
Boulanger, C., Schini, V.B., Moncada, S. \& VA.NHOUTte, P.M. 1990. Stimulation of cyclic GMP production in cultured endothelial cells of the pig by bradykinin, adenosine diphosphate, calcium ionophore A23187 and nitric oxide. Br 7 Pharmacol $101,152-156$.

BrüNE, B. \& LAPETINA, E.G. 1989. Activation of a cytosolic ADP-ribosyltransferase by nitric oxidegenerating agents. 7 Biol Chem 264, 8455-8458.

Della Bruna, R., Pinet, F., Corvol, P. \& Kurtz, A. 1991. Regulation of renin secretion and renin synthesis by second messengers in isolated mouse juxtaglomerular cells. Cell Phy'siol Biochem. 1, 98-110.

Furchgott, R.F. \& Vanhoutte, P.M. 1989. Endothelium-derived relaxing and contracting factors. F.ASEB 7 3, 2007-2018.

Furie, M.B., Cramer, E.B., Naprstek, B.L. \& Silverstein, S.M. Cultured endothelial cell monolayers that restrict the transendothelial passage of macromolecules and electric currents. 7 Cell Biol 98, 1033-1041.

Gardes, J., Poux, J.M., Gonzales, M.F., AlhencGelas, F. \& Menard, J. 1992. Decreased renin release and constant kallikrein secretion after injection of L-NAME in isolated perfused rat kidney. Life Sci 50, 987-993.

GaRG, U.C. \& Hassid, A. 1991. Nitric oxide decreases cytosolic free calcium in Balb/c3T3 fibroblasts by a cyclic GMP-independent mechanism. 7 Biol Chem 266, 9-12.

Hackenthal, E., Pall, M., Genten, D. \& Taugner, R. 1990. Morphology, physiology, and molecular biology of renin secretion. Physiol Rez, $\mathbf{7 0}$, $1067-1116$.

Heuzé-Joubert, I., Me.nnecier, P., Simonet, S., Laubie, M. \& Verbeuren, T.J. 1992. Effect of vasodilators, including nitric oxide, on the release of cGMP and CAMP in the isolated perfused rat kidney. Eur 7 Pharmacol 220, 161-171.

IGNARRo, L.J. 1989. Endothelium-derived nitric oxide: actions and properties. FASEB f 3, 31-36.

Kurtz, A., Kaissling, B., Busse, R. \& Baier, W. 1991. Endothelial cells modulate renin secretion from isolated mouse juxtaglomerular cells. 7 Clin Invest 88, 1147-1154.

LüCKHOFF, A., Busse, R., Winter, I. \& Bassenge, E. 1987. Characterization of a vascular relaxant factor released from cultured endothelial cells. Hypertension 9, 295-303.

LückHOFF, A. \& Busse, R. 1990). Calcium influx into endothelial cells and formation of endotheliumderived relaxing factor is controlled by the membrane potential. Pflügers Arch 416, 305-311.

Moe, O., Tejedor, A., Campbell, W.B., Alpern, R.J. \& HeNRICH, W.L. 1991. Effects of endothelin on in vitro renin secretion. Am 7 Physiol 260, E521-E.525. 
Moore, P.K., Al-Swayeh, O.A., Chong, N.W.S., Eva.vs, R.A. \& Gibsov, A. 1990. L- $N^{t \prime \prime}$-nitro arginine (L-NOARG), a novel, L-arginine-reversible inhibitor of endothelium-dependent vasodilation in vitro. Br 7 Pharmacol 99, 408-412.

Morgan-Boyd, R., Stewart, J.M., Vavrek, R.J. \& Hassid, A. 1987. Effects of bradykinin and angiotensin II on intracellular $\mathrm{Ca}^{2+}$ dynamics in endothelial cells. Am 7 Physiol 253, C588-C598.

Mülsch, A., BöHme, E. \& Busse, R. 1987. Stimulation of soluble guanylate cyclase by endothelium-derived relaxing factor from cultured endothelial cells. Eur 7 Pharmacol 135, 247-250.

Mundel, P., Bachmann, S., Bader, M., Fischer, A., Kummer, W., Mayer, B. \& Kriz, W. 1992. Expression of nitric oxide synthase in kidney macula densa cells. Kidney' Int 42, 1017-1019.

Murad, F., Mittal, C.K., Arnold, W.P., Katsuki, S. \& Kimura, H. 1978. Guanylate cyclase: activation by azide, nitro compounds, nitric oxide, and hydroxyl radical and inhibition by hemoglobin and myoglobin. Adv Cycl Nucl Res 9, 145-157.
Palmer, R.M.J., Ashton, D.S. \& Moncada, S. 1988. Vascular endothelial cells synthesize nitric oxide from L-arginine. Nature 333, 664666.

Scholz, H. \& KURTz, A. 1993. Endothelium derived relaxing factor is involved in the pressure control of renin secretion from the kidneys. 7 Clin. Invest. 91, 1088-1091.

SCHRICKER, K. \& KURTZ, A. Liberators of nitric oxide exert a dual effect on renin secretion from isolated mouse renal juxtaglomerular cells. Am 7 Physiol (in press).

Sigmon, D.H., Carretero, BO.A. \& Beierwaltes, W.H. 1992. Endothelium-derived relaxing factor regulates renin release in vivo. Am 7 Physiol 263, F256-F261.

Vidal, M.J., Romero, J.C., Vanhoutte, P.M. 1988. Endothelium-derived relaxing factor inhibits renin release. Eur 7 Pharmacol 149, 401-402.

Wilcox, C.S., Welch, W.J., Murad, F., Gross, S.S., TAYlOR, G., LeVI, R. \& SCHMIdT, H.H.H.W. 1992. Nitric oxide synthase in macula densa regulates glomerular capillary pressure. Proc Natl Acad Sci USA 89, 11993-11997. 